\title{
Water deprivation and the double- depletion hypothesis: common neural mechanisms underlie thirst and salt appetite
}

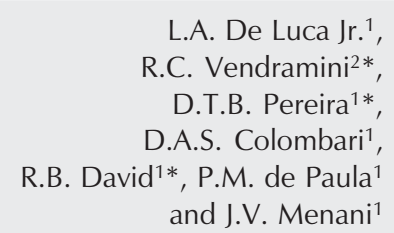

L.A. De Luca Jr. ${ }^{1}$,

R.C. Vendramini2*,

D.T.B. Pereira ${ }^{1 *}$,

D.A.S. Colombari ${ }^{1}$,

R.B. David ${ }^{1 *}$, P.M. de Paula ${ }^{1}$

and J.V. Menani ${ }^{1}$

\author{
${ }^{1}$ Departamento de Fisiologia e Patologia, Faculdade de Odontologia, \\ ${ }^{2}$ Departamento de Análises Clínicas, Faculdade de Ciências Farmacêuticas, \\ Universidade Estadual Paulista, Araraquara, SP, Brasil
}

Correspondence

L.A. De Luca Jr.

Departamento de Fisiologia e

Patologia

Faculdade de Odontologia, UNESP

Rua Humaitá, 1680

14801-903 Araraquara, SP

Brasil

Fax: +55-16-3301-6488

E-mail: lucajr@foar.unesp.br

Presented at the International

Symposium of Neuroendocrinology

"Neuroendocrine control of body

fluid homeostasis: past, present

and future". Ribeirão Preto, SP,

Brazil, September 1-3, 2006.

*These authors were enrolled in the Joint UFSCar/UNESP Graduate

Program in Physiological Sciences.

Research supported by CNPq and FAPESP. R.B. David and

D.T.B. Pereira were recipients of

graduate fellowships from FAPESP.

$\ldots \ldots \ldots \ldots \ldots \ldots$

Received October 11, 2006

Accepted March 29, 2007

$\ldots \ldots \ldots \ldots \ldots \ldots \ldots \ldots$

\begin{abstract}
Water deprivation-induced thirst is explained by the double-depletion hypothesis, which predicts that dehydration of the two major body fluid compartments, the extracellular and intracellular compartments, activates signals that combine centrally to induce water intake. However, sodium appetite is also elicited by water deprivation. In this brief review, we stress the importance of the water-depletion and partial extracellular fluid-repletion protocol which permits the distinction between sodium appetite and thirst. Consistent enhancement or a de novo production of sodium intake induced by deactivation of inhibitory nuclei (e.g., lateral parabrachial nucleus) or hormones (oxytocin, atrial natriuretic peptide), in water-deprived, extracellular-dehydrated or, contrary to tradition, intracellular-dehydrated rats, suggests that sodium appetite and thirst share more mechanisms than previously thought. Water deprivation has physiological and health effects in humans that might be related to the salt craving shown by our species.
\end{abstract}

Key words

- Water deprivation

- Dehydration

- Mineral preference

- Sodium appetite

- Cravings

\section{Introduction}

Sodium appetite and thirst are recognized complementary motivational states that drive a dehydrated animal to refill its major fluid compartments. Here we review the fact that water deprivation, the most common and natural form of inducing dehydration, activates not only thirst, but also sodium appetite.

\section{Thirst and sodium appetite results from water deprivation}

The double-depletion hypothesis of thirst predicts that water intake occurs as a re- sponse to a water deficit generated by liquid loss from the two major body compartments, i.e., the intra- and extracellular compartments (1). Thus, combined contraction and increased tonicity of the extracellular fluid (ECF) generates signals through the reninangiotensin system and osmoreceptors, respectively, that in turn combine centrally to produce thirst $(1,2)$. The double-depletion hypothesis is seminal to link these two mechanisms once considered separate to explain thirst in water-deprived animals. An early crucial set of experiments testing such a link was the attempt to suppress thirst by providing an intragastric or intravenous 
preload of the appropriate fluid in volumes predicted to be sufficient to refill each compartment, i.e., water for the intracellular compartment, and $0.15 \mathrm{M} \mathrm{NaCl}$ (i.e., isotonic solution) for the extracellular one $(3,4)$. Under carefully controlled conditions, the experiments essentially showed that thirst induced by water deprivation, as measured by the amount of water intake, is not completely suppressed by either preload alone, but by the two combined.

However, water-deprived rats ingested large amounts of isotonic $\mathrm{NaCl}$ after they received water preloads equivalent to the total volume of water they normally ingest. The authors concluded that intracellular overhydration, as induced by the ingestion of only water, did not reduce thirst, but only the desire to ingest water (4). The authors apparently assumed that isotonic $\mathrm{NaCl}$ intake is related to thirst, as also proposed by others to explain why cell-dehydrated rats also ingest isotonic $\mathrm{NaCl}(5,6)$. The main implication of this conclusion is that thirst drives a rat to ingest not only water, but also salt. One may agree in part with this view, because water is not always the most preferred liquid compared to mineral solutions under conditions of selective acute dehydration of either the extracellular or the intracellular compartment occurring within hours (7). Moreover, the total amount of fluid ingested by water-deprived rats is strongly influenced by taste $(8,9)$. However, there are two caveats about the view that thirst induces a desire to ingest water and salt, even if the salt is at isotonic concentration. First, according to what appears to be common sense, other investigators have related the expression of thirst only to water intake $(10,11)$. Second, the early experiments might have overlooked the possibility that sodium appetite, or the selective ingestion of sodium solutions and increased hypertonic $\mathrm{NaCl}$ intake, also results from water deprivation.

Several hours of water deprivation lead to appropriate physiological alterations that initiate a typical sodium appetite. For example, water-deprived rats, rabbits, sheep, or humans have not only contraction of the ECF, but also a negative sodium balance that results from a mechanism to buffer the increase in extracellular tonicity $(12,13)$. The first suggestion that water deprivation induces sodium appetite was based on these findings. When offered different types of mineral solutions simultaneously, water-deprived rats showed preference for sodium compared to other mineral solutions (14). This led us to ask whether angiotensin II mediates water deprivation-induced sodium appetite (15), as it does in the classic sodium depletion models such as adrenalectomy or diuretic injection combined with sodiumfree food (16,17). However, water-deprived rats may behave non-specifically by ingesting any type of fluid that becomes immediately available to them, as suggested by pilot experiments in our laboratory and the literature (8), making it hard to know when thirst ends and sodium appetite begins.

In order to properly distinguish thirst from sodium appetite, we developed a protocol, the water-depletion and partial ECFrepletion protocol or WD-PR, in which thirst is quenched by allowing the rat to drink from a burette filled with water prior to any access to sodium (15). Then, as water intake fades to nil, a solution of $\mathrm{NaCl}$ is provided in another burette and a sodium appetite test begins. The intake of $0.3 \mathrm{M} \mathrm{NaCl}$ in the sodium appetite test increases as a function of water deprivation period as shown at Figure 1. Animals that are not water deprived ingest less than $0.5 \mathrm{~mL}$ of this salt solution during the test. Preliminary unpublished data from our laboratory (Leite AS, Pereira DTB, Menani JV, De Luca LA Jr) are also consistent with the earlier proposal that water deprivation induces a preference for sodium (14) because mineral ingestion during this sodium appetite test is much in the form of sodium solutions.

Crucial physiological and neurological 
alterations in WD-PR associated with the subsequent ingestion of a sodium solution, in the sodium appetite test, are listed in Table 1 (18). Notice the negative sodium balance that results from reduced standardfood intake and from intracellular dehydration-induced natriuresis. The increase in plasma renin activity induced by hypovolemia remains elevated after thirst satiation; this elevation correlates with c-Fos expression in the subfornical organ and, partially, in the lamina terminalis. Neurons in these two structures are activated by angiotensin II and belong to encephalic circuits that subserve sodium appetite mediated by angiotensin II (19-24). The WD-PR protocol is instrumental for the execution of acute tests aimed at understanding the mechanisms of sodium appetite because it allows one to distinguish thirst from sodium appetite originating from the same treatment, i.e., water deprivation. Under these conditions, we have shown that blockade of converting enzyme or central angiotensin II receptors strongly inhibits the ingestion of hypertonic sodium solution during the sodium appetite test (15).

Therefore, water deprivation relates not only to thirst, but also to sodium appetite, thus leading to a new equation where water deprivation $=$ thirst + sodium appetite .

\section{Thirst and sodium appetite: two sides of the same coin?}

So much for water deprivation, but, considering water deprivation = double depletion, can one also conclude that double depletion $=$ thirst + sodium appetite ? The classical findings in this field of study say no, because, whereas extracellular dehydration facilitates, intracellular dehydration inhibits sodium appetite. However, the combination of earlier data with more recent experiments may impose a challenging "perhaps".

As mentioned above, since the early experiments testing the double-depletion hypothesis it has been known that animals in the early stages of dehydration, whether extra- or intracellular, ingest both water and isotonic $\mathrm{NaCl}$. However, ingestion of isotonic $\mathrm{NaCl}$ is not traditionally considered to represent sodium appetite. First, because animals in early extracellular or intracellular dehydration also ingest water, but reject hypertonic $\mathrm{NaCl}(4,7,25,26)$. Second, neither water nor sodium solution is preferred by early extracellularly or intracellularly dehydrated rats; whereas the former may ingest equal amounts of sodium and non-sodium solutions, as well as water, the latter show an uncanny preference for a potassium solution (7). Third, ECF hypertonicity is classically

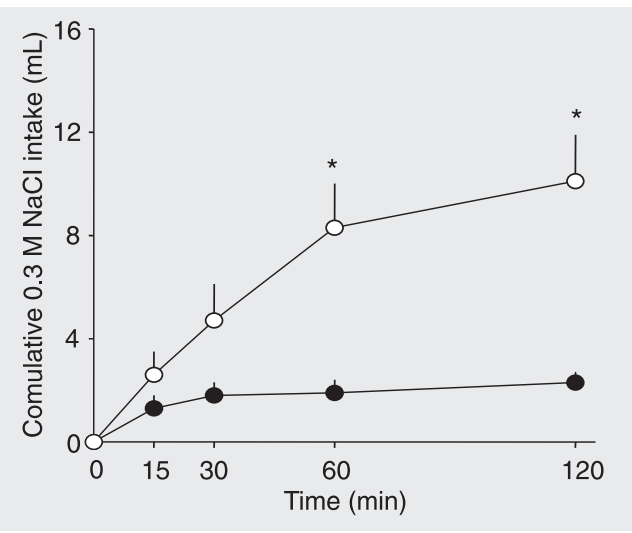

Figure 1. Cumulative 0.3 $\mathrm{M} \mathrm{NaCl}$ intake during a sodium appetite test by rats that had previous access only to water (partial extracellular fluid repletion, PR) after 24- (WD 24-PR) or 36-h (WD 36PR) water deprivation (WD). WD 24-PR (filled circles, $N=10$ ) and WD 36-PR (open circles, $\mathrm{N}=12$ ). Hydrated animals ingest less than $0.5 \mathrm{~mL} 0.3 \mathrm{M} \mathrm{NaCl}$ during a period equivalent to the sodium appetite test. $\mathrm{P}<0.05$ compared to WD 24-PR $(F(1,80)$ two-way repeated measures ANOVA and post hoc Student-Newman Keuls test).

Table 1. Fluid-electrolyte balance, hormonal activity, neuronal activity, blood pressure, and behavior of water-deprived rats prior to and after ingestion of water in the waterdepletion and partial extracellular fluid-repletion (WD-PR) protocol (from Ref. 18, with permission).

\begin{tabular}{ll}
\hline Prior to water intake (WD) & After only water intake (PR) \\
\hline Water deprivation & Partial volume repletion \\
Negative sodium balance & Negative sodium balance \\
Hypertonicity & Hypertonicity and thirst removed \\
Anorexia & Partial hypovolemia \\
Hypovolemia & RAS activity still highly elevated \\
Enhanced RAS activity & Normal mean arterial pressure \\
Normal mean arterial pressure & Removal of Fos-ir in SON \\
Fos-ir in SON & Partial reduced Fos-ir in lamina terminalis, \\
Fos-ir in lamina terminalis & but not in SFO \\
\hline
\end{tabular}

Partial extracellular fluid volume repletion is achieved by water intake and corresponds to the animal's internal status just prior to access to a sodium solution in the sodium appetite test. RAS = renin-angiotensin system; Fos-ir = Fos-like immunoreactivity; SON = supraoptic nucleus; SFO = subfornical organ. 
linked to inhibition of hypertonic $\mathrm{NaCl}$ intake (27).

Nevertheless, ECF hypertonicity might also induce hypertonic $\mathrm{NaCl}$ intake under special conditions. This was first suggested by studies showing enhanced hypertonic $\mathrm{NaCl}$ intake in animals either made hyponatremic with systemic hypertonic mannitol or injected systemically with hypertonic $\mathrm{NaCl}$ when hypovolemic $(28,29)$. Central inactivation or blockade of either central oxytocin or atrial natriuretic peptide receptors of these animals not only reduced the inhibition of hypertonic $\mathrm{NaCl}$ intake, but also induced hypertonic $\mathrm{NaCl}$ intake at amounts far above control. This enhanced hypertonic $\mathrm{NaCl}$ intake is similar to that shown by hypovolemic animals that have also their central oxytocin receptors blocked (29, but also see 30). More recently, it has been shown that enhanced hypertonic $\mathrm{NaCl}$ intake also occurs when serotonin receptors are blocked in the lateral parabrachial nucleus of either water-deprived, selectively extracellularly dehydrated or selectively intracellularly dehydrated rats; no hypertonic $\mathrm{NaCl}$ intake occurs in hydrated animals bearing this type of blockade (31-33).

Taken together, these data regarding inhibitory hormones and an inhibitory nucleus suggest that inhibitory circuits are a determinant factor of hypertonic $\mathrm{NaCl}$ intake, particularly in hyperosmotic animals. If so, it is possible that ECF hypertonicity and angiotensin II activate circuits that subserve thirst, and, contrary to common sense about ECF hypertonicity, also induce sodium appetite in the water-deprived rat, but the inhibitory factors activated by hypertonicity also produce strong inhibition of sodium appetite. Thus, a water-deprived rat that has immediate access to a salty solution may ingest it because it is searching for a liquid. If the animal first ingests only water instead, the inhibitory hypertonicity is removed, leaving only the facilitatory mechanisms, like angiotensin II, to act on sodium appetite. In addition, the more a salty solution is diluted, the less an inhibitory system interferes, thus allowing, for example, a cell-dehydrated rat with an intact lateral parabrachial nucleus to ingest isotonic $\mathrm{NaCl}$ as the most concentrated sodium solution in addition to water $(4,34)$.

The possibility that hypertonicity and angiotensin II induce thirst and sodium appetite in the rat resembles the behavior of marine fish that respond to both types of dehydration by ingesting salty water (35) and thus one may ask whether some of the neural basis of hydromineral intake in mammals was not inherited from their marine ancestors, and whether thirst and sodium appetite were the same thing in the past.

\section{Water deprivation, emergency reactions and addiction}

Water deprivation induces global responses involving not only the drive to ingest water and salt, but also activation of systems that act to conserve volume and guarantee normal tissue perfusion. Enhanced circulating angiotensin II, vasopressin and sympathetic tone contribute to avoid a decrease in arterial pressure under reduced extracellular volume $(36,37)$. Again, hormones may interact positively with hypertonicity. The increase in plasma osmotic pressure during water deprivation is not only important for vasopressin secretion, but also necessary for the increased sympathetic output that helps to sustain arterial pressure $(38,39)$.

Water deprivation also enhances the secretion of glucocorticoid, a hormone that helps the animals to cope with stress and that is likely to interact with angiotensin II to increase water and sodium intake (40-42). Water-deprived humans have similar physiological alterations and this species has learned that a guarantee against dehydration is to secure water resources and to adjust water and salt intake in order to avoid exces- 
sive water-lack hypovolemia or water-overconsumption hyponatremia (43-45). Some societies may still take water, and even salt, for granted, but this is not the rule all over the world because of either regional scarcity or reduced economic power (44). Nevertheless, whatever society is considered, a phenomenon called voluntary dehydration may be chronic in humans, and one can only speculate as to what consequences this phenomenon plus recurrent water deprivation may have for health and disease (46).

One guess is that water deprivation may contribute to the human craving for salt. Salt preference increases in humans subjected acutely to a protocol similar to the WD-PR (47). Repeated episodes of sodium depletion in rats lead to an enhanced sodium consumption that may share neural mechanisms with addiction $(48,49)$ and recently we have shown that rats with a history of repeated episodes of water deprivation have increased daily sodium consumption (50).

\section{Conclusion}

Water homeostasis has had a major survival role in the terrestrial environment. The same is true for sodium homeostasis. Water deprivation challenges both and thereby elicits appropriate mechanisms that assure the replacement of water and sodium. Therefore, when studying dehydration-related states we should not forget that sodium appetite is elicited by water deprivation. Perhaps the application of WD-PR protocols in humans and animals may provide novel insights for this type of study.

\section{Aknowledgments}

The authors thank Silvana A.D. Malavolta for excellent secretarial assistance.

\section{References}

1. Epstein AN. Epilogue: retrospect and prognosis. In: Epstein AN, Kissileff HR, Stellar E (Editors), The neuropsychology of thirst: new findings and advances in concepts. Washington: V.H. Winston and Sons; 1973. p 315-332.

2. Wilson KM, Rowland N, Fregly MJ. Drinking: a final common pathway? Appetite 1984; 5: 31-38.

3. Ramsay DJ, Rolls BJ, Wood RJ. Body fluid changes which influence drinking in the water deprived rat. J Physiol 1977; 266: 453-469.

4. Blass EM, Hall WG. Drinking termination: interactions among hydrational, orogastric, and behavioral controls in rats. Psychol Rev 1976; 83: 356-374.

5. Smith DF, Stricker EM. The influence of need on the rat's preference for dilute $\mathrm{NaCl}$ solutions. Physiol Behav 1969; 4: 407-410.

6. Stricker EM, Wolf G. Hypovolemic thirst in comparison with thirst induced by hyperosmolality. Physiol Behav 1967; 2: 33-37.

7. Pereira DT, David RB, Vendramini RC, Menani JV, De Luca LA Jr. Potassium intake during cell dehydration. Physiol Behav 2005; 85: 99-106.

8. Scalera G. Taste preference and acceptance in thirsty and rehydrated [correction of dehydrated] rats. Physiol Behav 2000; 71: 457468.

9. Rolls BJ, Rolls ET. Thirst. Cambridge: Cambridge University Press; 1982.

10. Epstein AN. Prospectus: thirst and salt appetite. In: Stricker EM (Editor), Neurobiology of food and fluid intake (Handbook of behavioral neurobiology). New York: Plenum Press; 1990. p 489-512.

11. Johnson AK, Thunhorst RL. The neuroendocrinology of thirst and salt appetite: visceral sensory signals and mechanisms of central integration. Front Neuroendocrinol 1997; 18: 292-353.

12. McKinley MJ, Denton DA, Nelson JF, Weisinger RS. Dehydration induces sodium depletion in rats, rabbits, and sheep. Am J Physiol 1983; 245: R287-R292.

13. Schoorlemmer GH, Evered MD. Water and solute balance in rats during $10 \mathrm{~h}$ water deprivation and rehydration. Can J Physiol Pharmacol 1993; 71: 379-386.

14. Weisinger RS, Denton DA, McKinley MJ, Nelson JF. Dehydrationinduced sodium appetite in rats. Physiol Behav 1985; 34: 45-50.

15. Sato MA, Yada MM, De Luca LA Jr. Antagonism of the reninangiotensin system and water deprivation-induced $\mathrm{NaCl}$ intake in rats. Physiol Behav 1996; 60: 1099-1104.

16. Sakai RR, Epstein AN. Dependence of adrenalectomy-induced sodium appetite on the action of angiotensin II in the brain of the rat. Behav Neurosci 1990; 104: 167-176.

17. Rowland NE, Rozelle A, Riley PJ, Fregly MJ. Effect of nonpeptide angiotensin receptor antagonists on water intake and salt appetite in rats. Brain Res Bull 1992; 29: 389-393.

18. De Luca LA Jr, Xu Z, Schoorlemmer GH, Thunhorst RL, Beltz TG, Menani JV, et al. Water deprivation-induced sodium appetite: humoral and cardiovascular mediators and immediate early genes. $\mathrm{Am}$ J Physiol Regul Integr Comp Physiol 2002; 282: R552-R559.

19. Fitts DA, Tjepkes DS, Bright RO. Salt appetite and lesions of the ventral part of the ventral median preoptic nucleus. Behav Neurosci 1990; 104: 818-827.

20. Weisinger RS, Denton DA, Di Nicolantonio R, Hards DK, McKinley 
MJ, Oldfield B, et al. Subfornical organ lesion decreases sodium appetite in the sodium-depleted rat. Brain Res 1990; 526: 23-30.

21. De Luca LA Jr, Galaverna O, Schulkin J, Yao SZ, Epstein AN. The anteroventral wall of the third ventricle and the angiotensinergic component of need-induced sodium intake in the rat. Brain Res Bull 1992; 28: 73-87.

22. Vivas L, Chiaraviglio E. The effects of reversible lidocaine-induced lesion of the tissue surrounding the anterior ventral wall of the third ventricle on drinking in rats. Behav Neural Biol 1992; 57: 124-130.

23. Rowland NE, Fregly MJ, Li BH, Han L. Angiotensin-related induction of immediate early genes in rat brain. Regul Pept 1996; 66: 25-29.

24. McKinley MJ, Allen AM, May CN, McAllen RM, Oldfield BJ, Sly D, et al. Neural pathways from the lamina terminalis influencing cardiovascular and body fluid homeostasis. Clin Exp Pharmacol Physiol 2001; 28: 990-992.

25. Stricker EM, Gannon KS, Smith JC. Thirst and salt appetite induced by hypovolemia in rats: analysis of drinking behavior. Physiol Behav 1992; 51: 27-37.

26. Stricker EM, Verbalis JG. Central inhibition of salt appetite by oxytocin in rats. Regul Pept 1996; 66: 83-85.

27. Fitzsimons JT, Wirth JB. The neuroendocrinology of thirst and sodium appetite. In: Kaufmann W, Krause DK (Editors), Central nervous control of $\mathrm{Na}^{+}$balance - relations to the renin-angiotensin system. Stuttgart: Georg Thieme Publishers; 1976. p 80-93.

28. Blackburn RE, Samson WK, Fulton RJ, Stricker EM, Verbalis JG. Central oxytocin inhibition of salt appetite in rats: evidence for differential sensing of plasma sodium and osmolality. Proc Natl Acad Sci USA 1993; 90: 10380-10384.

29. Blackburn RE, Samson WK, Fulton RJ, Stricker EM, Verbalis JG. Central oxytocin and ANP receptors mediate osmotic inhibition of salt appetite in rats. Am J Physiol 1995; 269: R245-R251.

30. Fitts DA, Thornton SN, Ruhf AA, Zierath DK, Johnson AK, Thunhorst $\mathrm{RL}$. Effects of central oxytocin receptor blockade on water and saline intake, mean arterial pressure, and c-Fos expression in rats. Am J Physiol Regul Integr Comp Physiol 2003; 285: R1331-R1339.

31. Menani JV, Thunhorst RL, Johnson AK. Lateral parabrachial nucleus and serotonergic mechanisms in the control of salt appetite in rats. Am J Physiol 1996; 270: R162-R168.

32. Menani JV, De Luca LA Jr, Johnson AK. Lateral parabrachial nucleus serotonergic mechanisms and salt appetite induced by sodium depletion. Am J Physiol 1998; 274: R555-R560.

33. De Luca LA Jr, Barbosa SP, Menani JV. Brain serotonin blockade and paradoxical salt intake in rats. Neuroscience 2003; 121: 10551061.

34. Pereira DT, Vendramini RC, David RB, Nozaki PN, Menani JV, De Luca LA Jr. Isotonic $\mathrm{NaCl}$ intake by cell-dehydrated rats. Physiol Behav 2002; 76: 501-505.
35. Takei Y. Comparative physiology of body fluid regulation in vertebrates with special reference to thirst regulation. Jpn J Physiol 2000; 50: $171-186$.

36. De Luca LA Jr, Sugawara AM, Menani JV. Brain versus peripheral angiotensin II receptors in hypovolaemia: behavioural and cardiovascular implications. Clin Exp Pharmacol Physiol 2000; 27: 437442.

37. Schrier RW. Water and sodium retention in edematous disorders: role of vasopressin and aldosterone. Am J Med 2006; 119: S47-S53.

38. Stricker EM, Sved AF. Controls of vasopressin secretion and thirst: similarities and dissimilarities in signals. Physiol Behav 2002; 77: 731-736.

39. Toney GM, Chen QH, Cato MJ, Stocker SD. Central osmotic regulation of sympathetic nerve activity. Acta Physiol Scand 2003; 177: 43-55.

40. Brooks VL, Qi Y, O'Donaughy TL. Increased osmolality of conscious water-deprived rats supports arterial pressure and sympathetic activity via a brain action. Am J Physiol Regul Integr Comp Physiol 2005; 288: R1248-R1255.

41. Ganesan R, Sumners C. Glucocorticoids potentiate the dipsogenic action of angiotensin II. Brain Res 1989; 499: 121-130.

42. Ma LY, McEwen BS, Sakai RR, Schulkin J. Glucocorticoids facilitate mineralocorticoid-induced sodium intake in the rat. Horm Behav 1993; 27: 240-250.

43. Convertino VA, Armstrong LE, Coyle EF, Mack GW, Sawka MN, Senay LC Jr, et al. American College of Sports Medicine position stand. Exercise and fluid replacement. Med Sci Sports Exerc 1996; 28: i-vii.

44. Ward DR. Water wars: drought, flood, folly, and the politics of thirst. New York: Riverhead Books; 2002.

45. Boscoe A, Paramore C, Verbalis JG. Cost of illness of hyponatremia in the United States. Cost Eff Resour Alloc http://www.resourceallocation.com/content/4/1/10; 2006.

46. Kleiner SM. Water: an essential but overlooked nutrient. J Am Diet Assoc 1999; 99: 200-206.

47. Takamata A, Mack GW, Gillen CM, Nadel ER. Sodium appetite, thirst, and body fluid regulation in humans during rehydration without sodium replacement. Am J Physiol 1994; 266: R1493-R1502.

48. Sakai RR, Fine WB, Epstein AN, Frankmann SP. Salt appetite is enhanced by one prior episode of sodium depletion in the rat. Behav Neurosci 1987; 101: 724-731.

49. Clark JJ, Bernstein IL. A role for D2 but not D1 dopamine receptors in the cross-sensitization between amphetamine and salt appetite. Pharmacol Biochem Behav 2006; 83: 277-284.

50. Pereira DT, David RB, Menani JV, De Luca LA Jr. Episodes of water deprivation enhance daily hypertonic $\mathrm{NaCl}$ intake in rats. Braz $J$ Med Biol Res 2002; 35: 465-468. 